\title{
THE IODIDE TRAPPING AND BINDING FUNCTIONS OF THE THYROID
}

\author{
By SOLOMON A. BERSON AND ROSALYN S. YALOW
}

(From the Radioisotope Unit, Veterans Administration Hospital, Bronx, New York)

(Submitted for publication August 12, 1954 ; accepted October 20, 1954)

McGinty and Sharp (1) demonstrated that the thyroid glands of rats treated with propylthiouracil retained the ability to concentrate iodide ion but failed to bind the iodine in an organic form. VanderLaan and VanderLaan (2) and Stanley and Astwood (3) showed also that thyroidal iodide, "trapped" under the influence of the antithyroid drugs, could be rapidly discharged from the gland by the administration of thiocyanate ion. Iodine accumulation by the thyroid has therefore been considered a two-step function; the first is concerned with the concentration (trapping) of iodide at a level higher than that in the circulating plasma, while the second, in itself a complicated process composed of several chemical stages, is represented by organic binding of the trapped iodide.

Several authors have inquired into the kinetics of thyroidal iodide trapping and binding (4-6). On the assumption that equilibration of plasma and thyroidal inorganic iodide ${ }^{131}$ (iodide trapping) is instantaneous following intravenous administration of $\mathrm{I}^{131}$, Ingbar $(4,5)$ calculated that thyroidal binding of trapped iodide proceeded at average rates of $1 \frac{1}{2}$ per cent per minute in euthyroid subjects and $6 \frac{1}{2}$ per cent per minute in patients with Graves' disease. Wollman (6) assumed that the plasma iodide ${ }^{131}$ concentration remained constant or decreased at a single exponential rate and considered the sequelae of several theoretical alternatives for the relative rates of trapping and binding. In the present study an analysis is presented which permits evaluation of the rates of trapping and binding from observed data without assumptions regarding either process or restrictions in the behaviour of the plasma iodide $^{131}$ concentration. The results of the experimental investigations indicate an extremely rapid binding of trapped iodide in the untreated gland and lead to the conclusion that trapping rather than binding is the rate-limiting step of thyroidal iodine accumulation.

\section{TECHNICAL METHODS}

Subjects received intravenous injections of 15 to $200 \mu \mathrm{C}$ carrier-free $\mathrm{NaI}^{131}$ in normal saline solution. Assay of thyroidal radioactivity was performed with a bismuthwalled Geiger counter and a scaling circuit connected to a Streeter-Amet register which automatically printed the cumulative counts at minute intervals, as previously described (7). The sensitivity of this arrangement was 110 counts per minute per $\mu \mathrm{c} \mathrm{I}^{181}$ above a background of 60 counts per minute. Five ml. samples of packed erythrocytes, plasma and urine were counted in a well-type scintillation counter with a sensitivity of $1.00 \times 10^{\circ}$ counts per minute per $\mu \mathrm{C} I^{131}$ above a background of 200 counts per minute. $\mathrm{PBI}^{131}$ and iodide ${ }^{131}$ were determined separately utilizing the plasma/RBC ratio of $I^{131}$ as previously described $(8,9)$.

Extrathyroidal radioactivity "seen" by the counter was determined, for each subject, from the counting rate over the neck following discharge of trapped thyroidal iodide (binding inhibited by Tapazole ${ }^{(3)}$ by the intravenous administration of $1.0 \mathrm{gm}$. NaSCN. Corrections for extrathyroidal activity at all times could then be made according to methods previously described (7). In euthyroid subjects, whether or not binding was blocked, the counting rate during the second minute following intravenous injection of $\mathrm{NaI}^{131}$ was usually in excellent agreement with the extrathyroidal radioactivity determined by the method described above. These observations confirm the premise, previously made (7), that there is virtually no thyroidal I $^{12}$ accumulation this early in normal glands. In hyperthyroid subjects, however, appreciable amounts of radioactivity were occasionally present in the thyroid even during the first few minutes so that the extrathyroidal level was sometimes below the earliest recorded counts. The geometry of the counting system was such that the extrathyroidal radioactivity "seen" by the counter was 12 to 13 per cent of the total extrathyroidal radioactivity in almost all subjects, which is in agreement with the total neck activity recorded by this arrangement in athyreotic subjects.

In one group of hyperthyroid subjects, "binding" and "trapping" studies ${ }^{1}$ were carried out on the same day in the following manner. Determinations of radioactivity in thyroid and blood were made over a 30 to 35-minute period following the intravenous injection of a small tracer dose of $\mathrm{NaI}^{131}(15$ to $20 \mu \mathrm{c})$. Fifty milligrams of Tapa-

1 "Trapping" study refers to a tracer experiment performed during Tapazole ${ }^{\left({ }^{2}\right.}$ inhibition of binding. "Binding" study refers to a tracer experiment performed in the absence of Tapazole inhibition. 
zole (1-methyl 2-mercaptoimidazole) were then given by mouth and 60 to 90 minutes later a repeat study was performed with a dose of $I^{131}$ about 10 to 15 times as great as the first. Observations of thyroidal and blood radioactivities were again obtained and appropriately corrected for the small residual activities of the first dose. One-half to two hours after administration of the second tracer, 1.0 gram NaSCN was injected intravenously.

\section{ANALYSIS}

\section{Thyroidal iodide trapping}

When organic binding of iodide is completely blocked with adequate doses of Tapazole ${ }^{\circledR}$, thyroidal radioactivity increases with time reaching a peak value within a few minutes to an hour or two following intravenous injection of $\mathrm{NaI}^{131}$, and then declines parallel with the plasma concentration until all the radioactivity is cleared from the body by renal excretion (Figure 1). Under these conditions the rate of removal from the body is directly dependent on the renal plasma iodide clearance rate and inversely related to the fraction of total iodide trapped by the thyroid. That thyroidal $I^{121}$ is not organically bound but is in equilibrium with plasma iodide is indicated by the parallelism of thyroidal and plasma curves of radioactivity (Figures 1,2 ) and by the ready dischargeability of thyroidal radioactivity with $\mathrm{NaSCN}$ (Figure 2). If the cumulative urinary excretion of $\mathrm{I}^{131}$ is subtracted from the dose administered, the trapped thyroidal iodide ${ }^{131}$ at equilibrium may be expressed as the thyroidal fraction of the dose retained in the body (fr $\mathrm{I}_{\mathrm{ret}}^{131}$ ). The extent of trapping may also be expressed as liters equivalent of plasma content ("thyroidal iodide space"), or as milliliters plasma equivalent per gram of thyroid tissue (thyroid/plasma ratio).

Accumulation of iodide by the thyroid trap could usually not be described adequately by a single exponential rate, since the rate of approach of thyroidal radioactivity to the asymptotic value was generally much more rapid immediately following injection than subsequently (Figure 2). It is not necessary to postulate several thyroidal compartments equilibrating with plasma at different rates to ex-

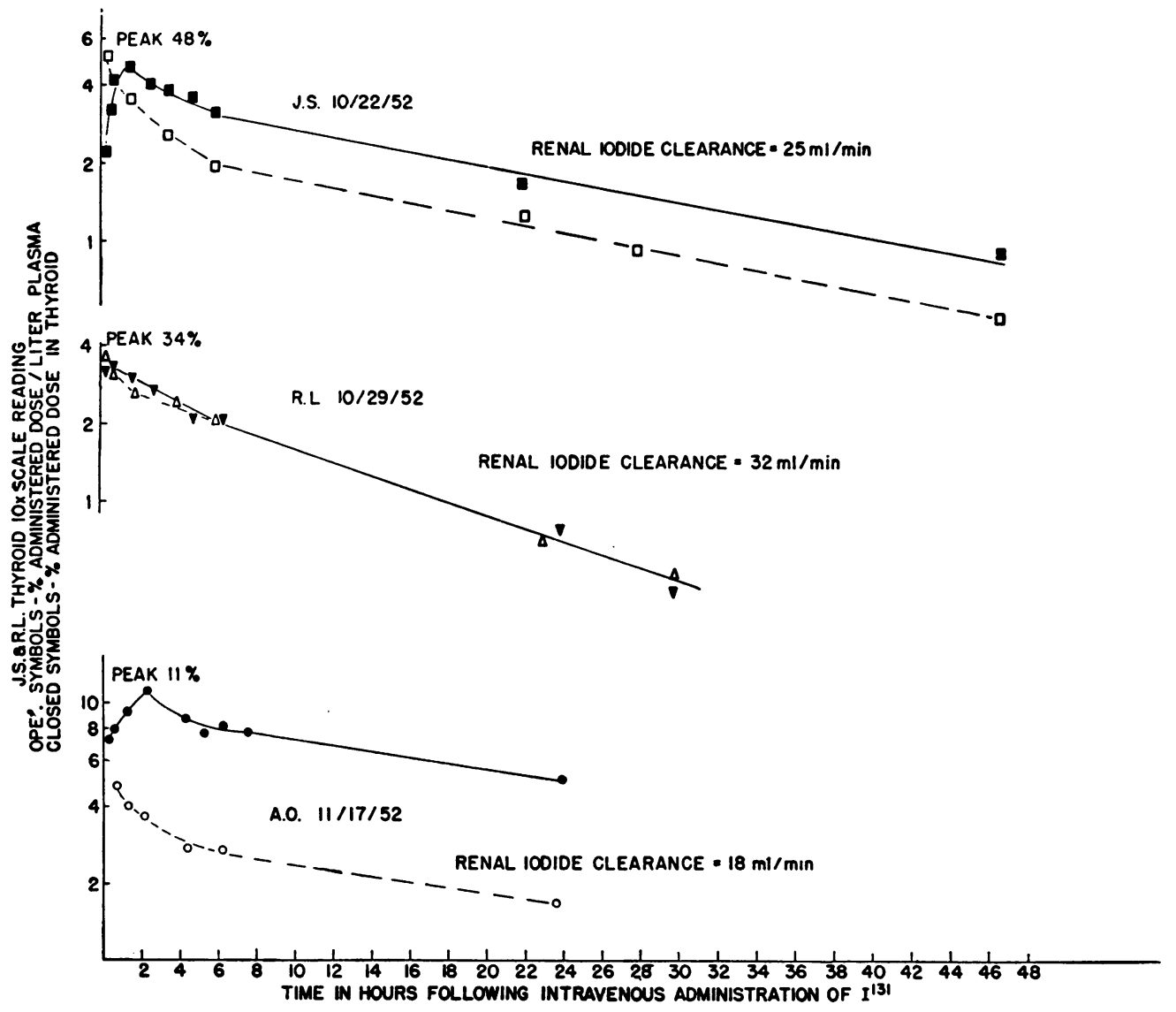

Fig. 1. Characteristic Thyroidal and Plasma Radioactivity Curves in Subjects Receiving 25 Mg. Tapazoled Every 6 Hours

R. L. and J. S., hyperthyroid; A. O., hyperthyroid but had received $I^{121}$ therapy $21 / 2$ months previously. The slopes of the curves can be correlated roughly with the rates of the renal clearance. 


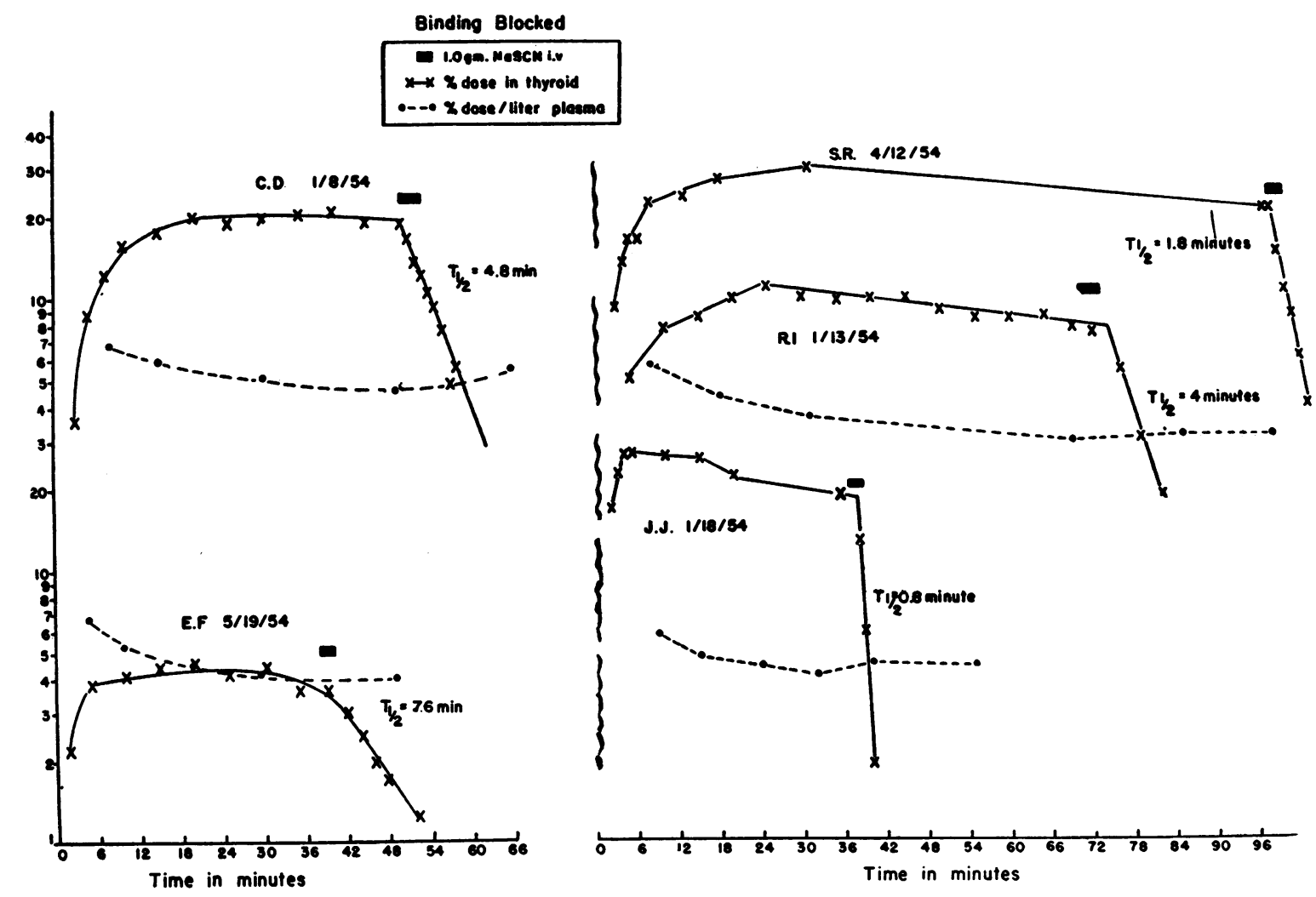

Fig. 2. Effect of Thiocyanate on "Trapped" Thyroidal Iodide ${ }^{18}$, Binding Blocked

$I^{12}$ injected intravenously at time 0,60 to 90 minutes following the oral administration of $50 \mathrm{mg}$. Tapazole. E. F. euthyroid; others hyperthyroid. The fall in thyroidal activity after injection of thiocyanate is exponential. Although not analyzed in the figure, the approach of thyroidal activity to its asymptote usually did not occur at a single exponential rate.

plain this observation since it is accounted for by the gradually increasing extrathyroidal space of distribution of the iodide ${ }^{181}$ tracer. Inasmuch as the time course of extrathyroidal iodide ${ }^{181}$ distribution is itself the sum of several different exponential terms, a precise solution of the kinetics of iodide trapping by means of equations describing the blood and thyroid curves is virtually impossible.

However, the rate constants of transfer between the thyroid "trap" and the plasma may be evaluated as follows.

Plasma iodide ${ }^{181}$, following intravenous administration, mixes with iodide in the thyroid and in other extrathyroidal spaces. Let $\mathrm{V}$ be the plasma volume, $\mathrm{T}$ be the total thyroidal radioactivity and $P$ be the concentration of radioactivity in the plasma at any time, $t$, under conditions of Tapazole ${ }^{\circledR}$ blockage. Then,

$$
\frac{\mathrm{dT}}{\mathrm{dt}}=-\lambda_{\mathrm{TP}} \mathrm{T}+\lambda_{\mathrm{PT} P V}
$$

where $\lambda_{\text {TP }}$ and $\lambda_{\text {PT }}$ are the rate constants ${ }^{2}$ of transfer of

${ }^{2}$ During the short term experiments required for equilibration of iodide ${ }^{12}$ with the thyroid trap a steady state with respect to stable iodide ${ }^{127}$ may be assumed. Although iodide between thyroid and plasma in the order of the subscript designations. Now, let $R$ be the total amount of $I^{181}$ retained within the body and $T^{\prime}$ and $P^{\prime} V$ be the fractions of $R$ in the thyroid and plasma, respectively, at any time, t. Then $T^{\prime}=\frac{T}{R}$ and $P^{\prime}=\frac{P}{R}$. Substituting in equation (1),

$$
\frac{\mathrm{d}\left(\mathrm{RT} \mathrm{T}^{\prime}\right)}{\mathrm{dt}}=-\lambda_{\mathrm{TP}} \mathrm{R} \mathrm{T}^{\prime}+\lambda_{\mathrm{PT}} \mathrm{R} \mathrm{P}^{\prime} \mathrm{V}
$$

Completing the derivative of the left hand side of the equation and solving for $\frac{\mathrm{dT}^{\prime}}{\mathrm{dt}}$.

$$
\frac{\mathrm{dT}^{\prime}}{\mathrm{dt}}=-\left(\lambda_{\mathrm{TP}}+\frac{\mathrm{dR} / \mathrm{dt}}{\mathrm{R}}\right) \mathrm{T}^{\prime}+\lambda_{\mathrm{PT}} \mathrm{P}^{\prime} \mathrm{V}
$$

At equilibrium, the radioactivity (in terms of the fraction of $I^{181}$ retained within the body) entering the thyroid

this condition is not essential to the analysis, it permits treatment of the transfer rates as constants in the absence of an assumption of first order kinetics for the trapping processes. 

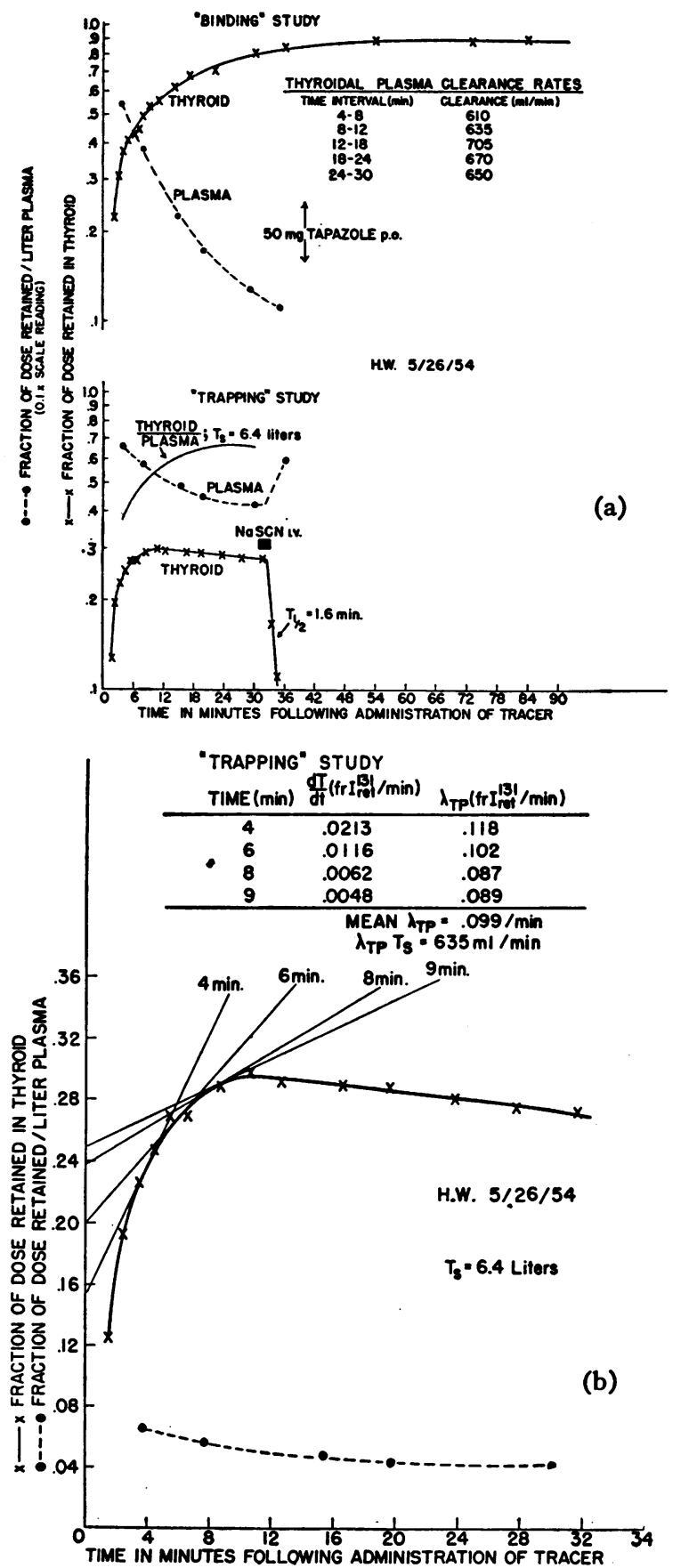

Fig. 3. Study in Hyperthyroid Subject H. W.

(a) Upper curves-thyroidal and plasma radioactivities during "binding" study. Tapazole administered $40 \mathrm{~min}$ utes after injection of tracer.

Lower curves-"trapping" study. Im tracer injected 60 minutes after the administration of the Tapazole indicated in the upper half of the figure. The time course for the total thyroid/plasma ratio in liters is also shown. In cases of rapid equilibration this ratio reaches a peak is equal to that leaving. Then, $\frac{\mathrm{dT}_{\mathrm{oq}}^{\prime}}{\mathrm{dt}}=0^{2}$ and

$$
\left(\lambda_{T P}+\frac{d R / d t}{R}\right) T^{\prime}{ }_{Q q}=\lambda_{P T} P_{\odot Q}^{\prime} V
$$

Now let $T$, be the thyroidal iodide space in liters equivalent of plasma so that $T_{0}=\frac{T_{e q}^{\prime}}{P_{e q}^{\prime}}$. Then, from (3) and (4), and solving for $\lambda_{T P}+\frac{d R / d t}{R}$

$$
\lambda_{\mathrm{TP}}+\frac{\mathrm{dR} / \mathrm{dt}}{\mathrm{R}}=\frac{\mathrm{dT} / \mathrm{dt}}{\mathrm{P}^{\prime} \mathrm{T}_{\mathrm{s}}-\mathrm{T}^{\prime}}
$$

Now, when the rate of loss of $I^{181}$ from the body $\left(\frac{\mathrm{dR} / \mathrm{dt}}{\mathrm{R}}\right)$ is small compared to $\lambda_{\mathrm{TP}}, \frac{\mathrm{dR} / \mathrm{dt}}{\mathrm{R}}$ may be neglected at all times ${ }^{4}$ and equation (5) becomes

$$
\lambda_{\mathrm{TP}}=\frac{\mathrm{dT}^{\prime} / \mathrm{dt}}{\mathrm{P}^{\prime} \mathrm{T}_{\mathbf{B}}-\mathrm{T}^{\prime}}
$$

$\mathrm{dT}^{\prime} / \mathrm{dt}$ is the slope of the curve of thyroidal radioactivity (in terms of fr $\mathrm{I}_{\mathrm{rot}}^{131}$ ) vs. time at any time. $\lambda_{\mathrm{TP}}$ can then be evaluated from simultaneous experimental observations of $\mathrm{dT}^{\prime} / \mathrm{dt}, \mathrm{T}^{\prime}$ and $\mathrm{P}^{\prime}$ as demonstrated in Figure 3.

From equation (4), and again neglecting $\frac{d R / d t}{R}$,

$$
\lambda_{P T} \mathrm{~V}=\lambda_{T P} T_{\bullet}
$$

'Although iodide ${ }^{1 n}$ excretion does effect a continual lowering of the actual thyroidal radioactivity, the equilibrium situation defined for iodide ${ }^{131}$ in terms of the fraction of the dose retained is theoretically valid.

4 The rate of excretion of iodide $1 \mathrm{ln}$ was 4 to 9 per cent per hour in the cases studied while $\lambda_{\text {TP }}$ ranged from $1 \frac{1}{2}$ to 10 per cent per minute as given in Table I. Thus, since $\lambda_{\text {TP }}$ is at least 10 to 100 times as great as $\frac{\mathrm{dR} / \mathrm{dt}}{\mathrm{R}}$, the simplifying approximation inherent in equation (6) may produce an error of 1 to 10 per cent in $\lambda_{\mathrm{TP}}$. The error generally was about 2 to 3 per cent. This error can be eliminated if frequent urine collections are made during the period of iodide equilibration between plasma and thyroid trap. For cases where this is inconvenient, an alternative analysis which permits evaluation of $\lambda_{\text {TP }}$ with a maximum error of less than 1 per cent is presented in the Appendix.

slightly higher than the equilibrium value $\left(T_{0}\right)$. A more precise, slightly lower value for $T$. would have been obtained if the study had been continued longer.

(b) Thyroidal and plasma radioactivities of "trapping" study in (a) transferred to a linear plot to permit evaluation of the slopes $\left(\mathrm{dT}^{\prime} / \mathrm{dt}\right)$ of the thyroid curve. $\lambda_{\mathrm{TP}}$ is then obtained by substitution in equation 6 of the text. In most instances equilibration is more prolonged and $\mathrm{dT}^{\prime} / \mathrm{dt}$ may be evaluated at many points up to 30 or 40 minutes or more. 


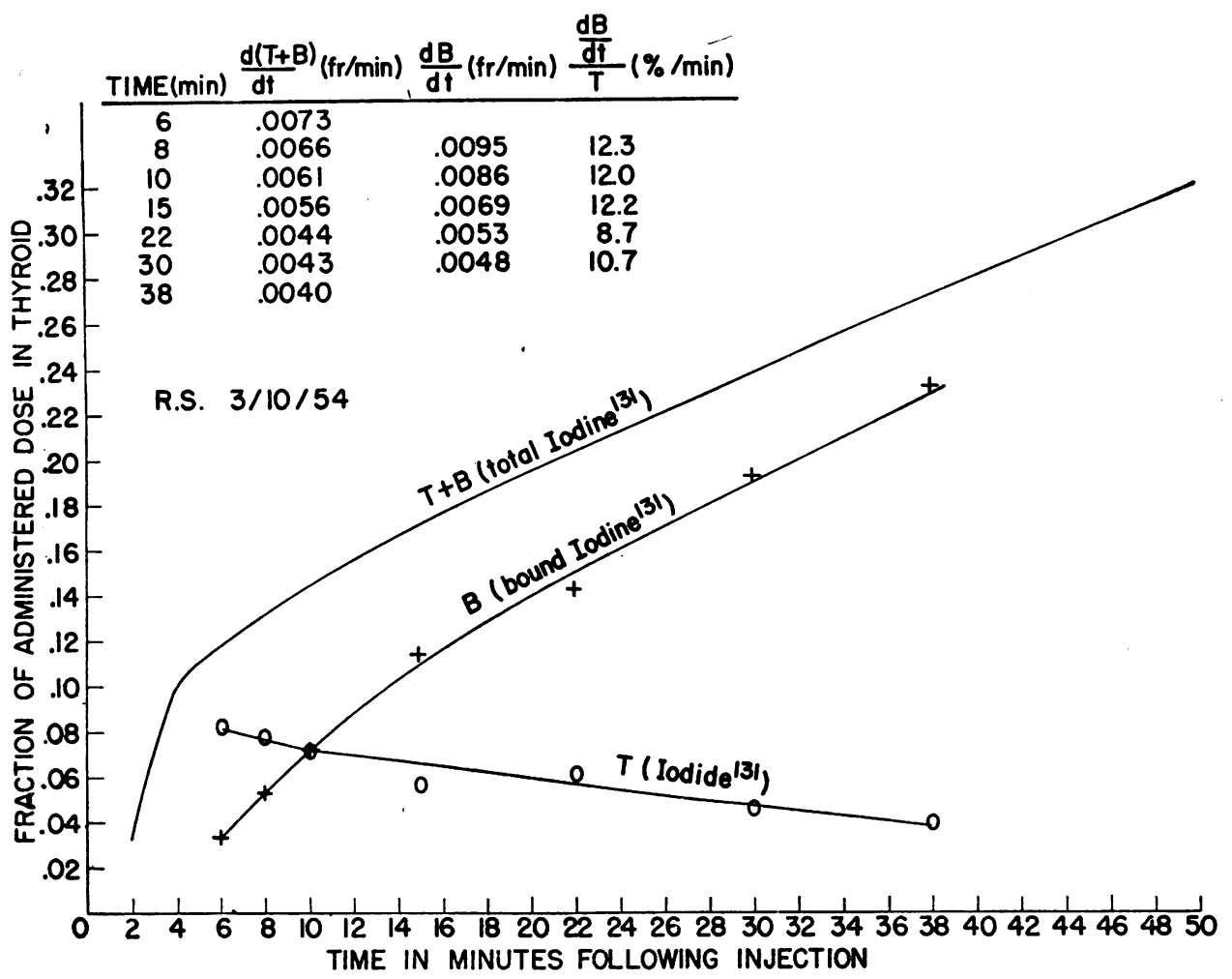

Fig. 4. Observed Total Thyrotdal Radioactivity $(T+B)$ and Calculated Bound Iodine (B) and Iodide (T) Radioactivity in Subject R. S. From "Binding" Study

This subject had been treated with $\mathrm{I}^{212}$ for hyperthyroidism 5 months previously. There was temporary improvement but patient was in relapse at the time of this study.

A smooth curve has been drawn through the observed points for total iodine ${ }^{\text {in }}(T+B)$. The slopes $d(T+B) / d t$ of this curve at different times are given in the table at the top of the figure. Analysis of the curves in the "trapping" study (as for $H$. W. in Figure $3 \mathrm{~b}$ ) gave $\lambda_{\mathrm{PTV}} \mathrm{V}=143 \mathrm{ml}$. per min. and $\lambda_{\mathrm{TP}}=.050 \mathrm{~min}^{-1}$ (Table I). The values for $\mathrm{d}(\mathrm{T}+\mathrm{B}) / \mathrm{dt}$, $\lambda_{\mathrm{PT} V} \mathrm{~V}$ and $\lambda_{\mathrm{TP}}$ were then substituted into equation 11 of the Text to yield the values for $\mathrm{T}$ at the corresponding times. Values for B were obtained by subtracting the calculated points of $T$ from corresponding points of $(T+B)$. Slopes of $B$ at different times, given in the table at the top of figure, were then divided by the corresponding values for $T$ to give the rate of binding of trapped iodide $(\mathrm{dB} / \mathrm{dt} / \mathrm{T})$ at the different times. The rate of binding is fairly constant at about 9 to 12 per cent per minute. The thyroidal clearance (not shown) after 10 minutes was $86 \mathrm{ml}$. per min. Plasma samples were not taken early enough in this case to demonstrate the higher thyroidal clearance during the first few minutes.

$\lambda_{\mathrm{PTV}} \mathrm{represents} \mathrm{the} \mathrm{volume} \mathrm{of} \mathrm{plasma} \mathrm{containing} \mathrm{that}$ amount of iodide which is transferred to the thyroid trap per unit time. If equilibrium between plasma and thyroid trap is established during a single circulation through the thyroid, this volume flow represents the thyroidal plasma flow. If the plasma leaving the thyroid has not come into equilibrium with the thyroid trap, then this flow is

- If $\mathrm{RBC}$ iodide, which is in rapid equilibrium with plasma iodide, is also available to the thyroid trap during circulation through the thyroid, then the figures for plasma flow may be anything up to $\mathbf{4 0}$ per cent too high since at normal hematocrit levels the total iodide content of erythrocytes is about $\mathbf{4 0}$ per cent that of the plasma. smaller than the thyroidal plasma flow. The volume flow of plasma thus calculated has therefore been termed the "equilibrating thyroidal plasma flow" since it is virtually identical to the ideal volume flow representing that portion of the total thyroidal plasma flow which has come into equilibrium with the thyroid trap before leaving the

- The true equilibrating flow is that flow from which only approximately 99.0 to 99.95 per cent of plasma iodide $^{12}$ is transferred to the thyroid trap, assuming thyroid/plasma ratios of $20 / 1$ to $500 / 1$ and thyroidal blood volumes of 20 per cent of thyroid weight. However this is virtually identical to $\lambda_{P T} V$, that flow from which 100 per cent of the iodide ${ }^{12}$ is transferred. 
thyroid. Under conditions permitting binding of trapped iodide, the equilibrating thyroidal plasma flow would equal the thyroidal plasma iodide clearance if binding were instantaneous.

\section{Thyroidal iodide binding}

Let $T$ and $B$ be the quantities of trapped radioiodide and organically bound radioiodine in the thyroid at any time, $t$, following the administration of a tracer dose of $\mathrm{NaI}^{181}$. Let $\lambda_{\text {TP }}$ and $\lambda_{\text {PT }}$ be the transfer coefficients for iodide between thyroid and plasma as before and $\lambda_{\mathrm{TB}}$ be the rate of binding of trapped thyroidal iodide. Then

$$
\begin{gathered}
\frac{d T}{d t}=\lambda_{P T} P V-\lambda_{T P} T-\lambda_{T B} T \\
\frac{d B}{d t}=\lambda_{T B} T \\
\frac{d(T+B)}{d t}=\frac{d B}{d t}+\frac{d T}{d t}=\lambda_{P T} P V-\lambda_{T P} T
\end{gathered}
$$

where $(T+B)$ is the total thyroidal radioactivity. It is assumed that negligible amounts of bound iodine have been released from the thyroid or degraded within the thyroid during the period of these studies. Solving for $T$,

$$
T=\frac{\lambda_{\mathrm{PT} V P}-\frac{\mathrm{d}(\mathrm{T}+\mathrm{B})}{\mathrm{dt}}}{\lambda_{\mathrm{TP}}}
$$

When the values for $\lambda_{\text {TP }}$ (from equation 6 ) and $\lambda_{P T} V$ (from equation 7 ) obtained from the analysis of the curves during the "trapping" study, are substituted in equation (11), T, at any time, is seen to be defined by the plasma concentration of iodide ${ }^{1 n}(P)$ and the slope of the observed thyroidal radioactivity curve $\left(\frac{\mathrm{d}(\mathrm{T}+\mathrm{B})}{\mathrm{dt}}\right)$ at the same time. Therefore the curve of thyroidal radioiodide (T) can be constructed (Figure 4). By subtracting each point on the curve $T$ from the observed total thyroidal radioactivity curve $(T+B)$, the curve for organically bound

TABLE I

Data pertaining to trapped thyroidal iodide and its discharge by thiocyanate

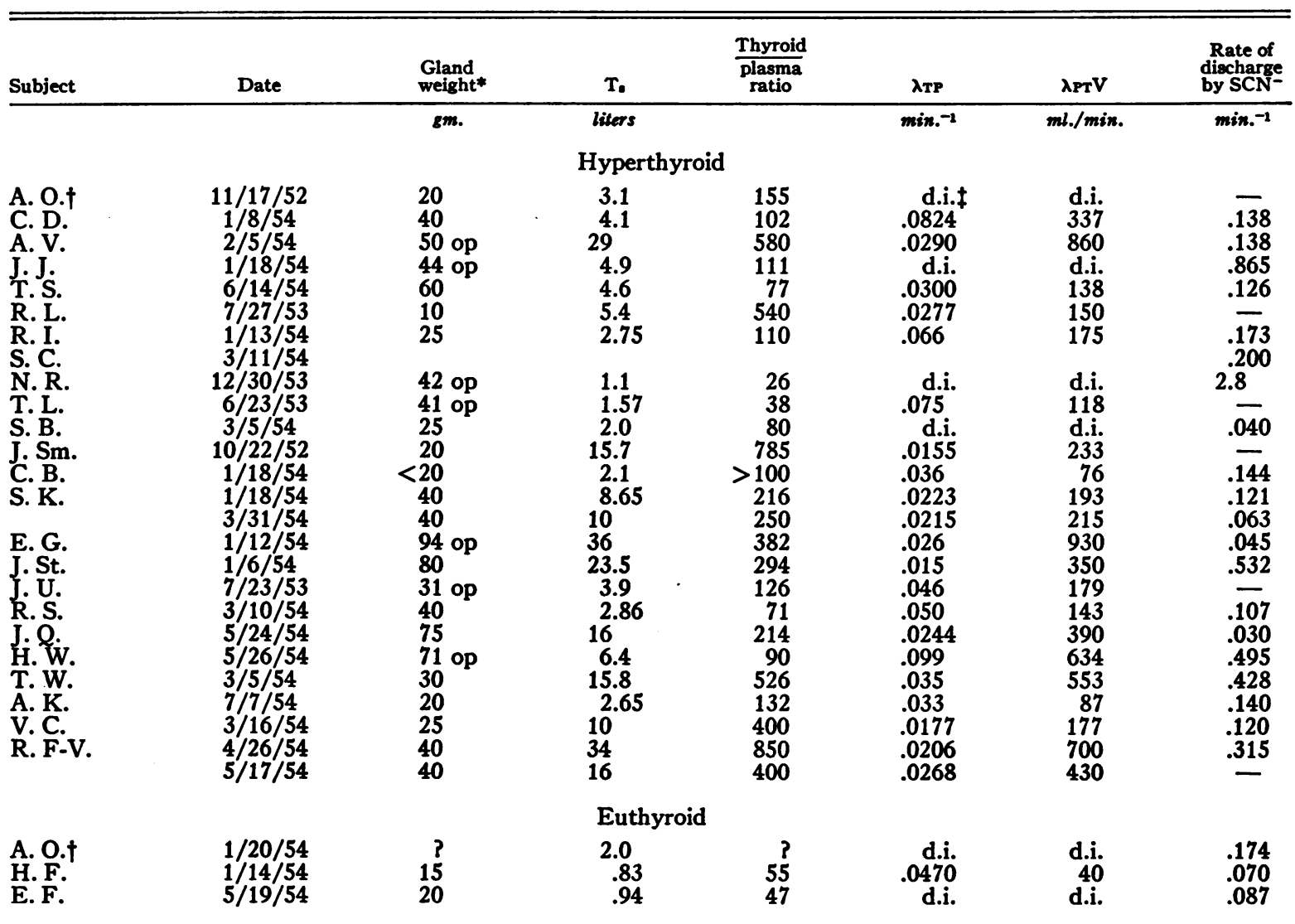

* Two grams added to weights of glands removed at operation. In those cases not subjected to surgery weights were estimated by palpation. In our hands these estimates are frequently in error by as much as 50 per.cent so that the thyroid/plasma ratios are to be regarded as approximate.

t Treated with 4.5 mc. I $1313 / 52$; clinically hyperthyroid $11 / 17 / 52$, clinically euthyroid $1 / 20 / 54$.

$\mp$ d.i. - Data insufficient; usually blood samples were not taken early enough to evaluate rapid rate of equilibration. 

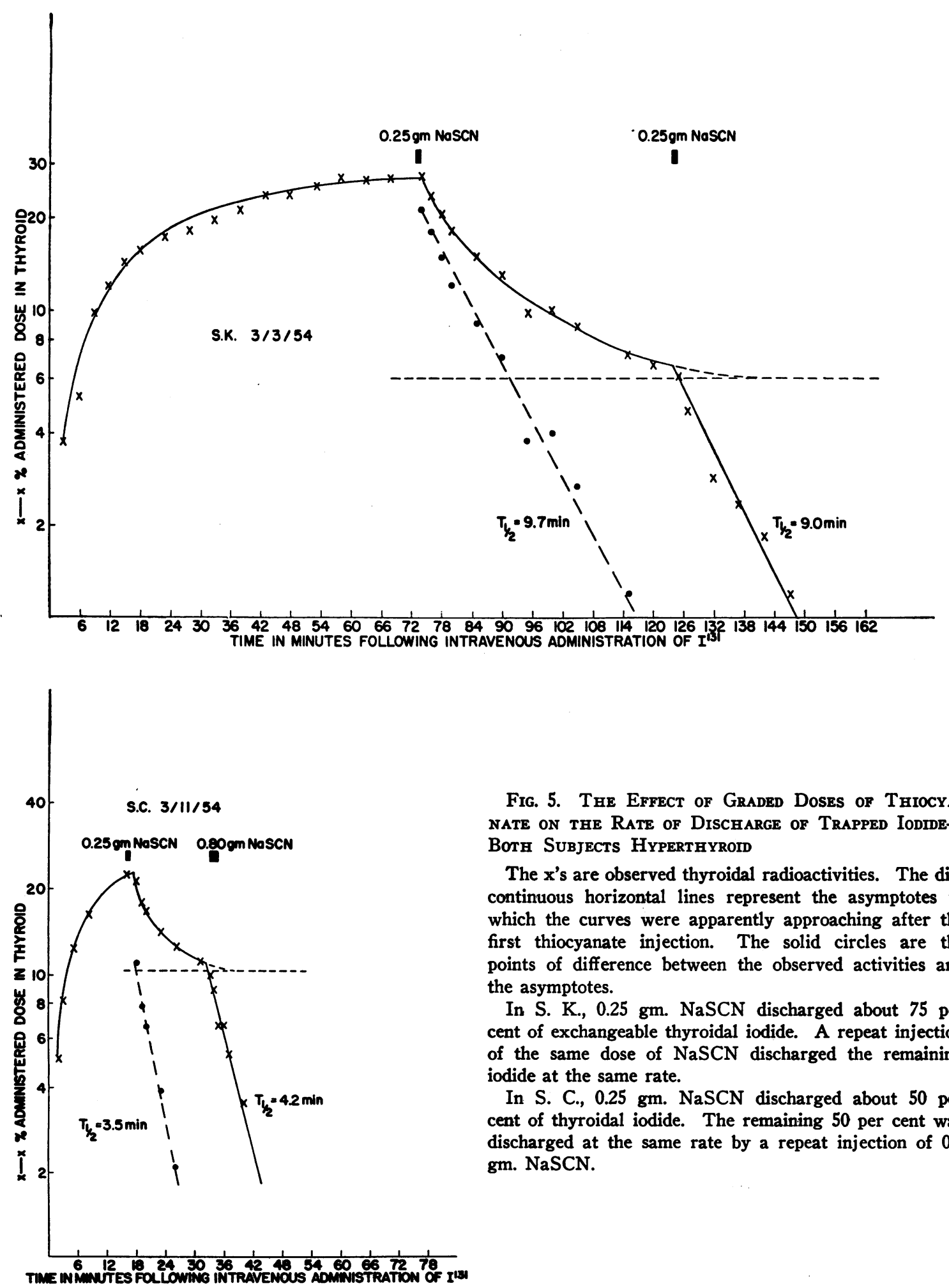

Fig. 5. The Efrect of Graded Doses of ThiocyaNate on the Rate of Discharge of Trapped IodideBOTH SUbJects HyperthyroId

The $x$ 's are observed thyroidal radioactivities. The discontinuous horizontal lines represent the asymptotes to which the curves were apparently approaching after the first thiocyanate injection. The solid circles are the points of difference between the observed activities and the asymptotes.

In S. K., $0.25 \mathrm{gm} . \mathrm{NaSCN}$ discharged about 75 per cent of exchangeable thyroidal iodide. A repeat injection of the same dose of $\mathrm{NaSCN}$ discharged the remaining iodide at the same rate.

In S. C., $0.25 \mathrm{gm}$. NaSCN discharged about 50 per cent of thyroidal iodide. The remaining 50 per cent was discharged at the same rate by a repeat injection of 0.8 gm. NaSCN. 
iodine (B) can be constructed (Figure 4). Then from (9),

$$
\lambda_{\mathrm{TP}}=\frac{\mathrm{dB} / \mathrm{dt}}{\mathrm{T}}
$$

Estimates of the rate of binding of trapped iodide $\left(\lambda_{\mathrm{TB}}\right)$ can then be made from the slope of the bound iodine curve (B) and the value for trapped iodide (T) at the same time. To decrease the magnitude of the experimental errors, the ratio, $\frac{d B / d t}{T}$, may be obtained at a number of different time points on the same set of curves and the results averaged (Figure 4).

From the plasma concentration curve $(P)$ and the trapped iodide curve (T), the thyroid/plasma ratio can be obtained at any time and compared with the ratio observed when binding is prevented by Tapazole ${ }^{\text {(2) }}$.

\section{RESULTS}

\section{Thyroidal Trapping of Iodide; Binding Inhibited} by Tapazole

Values for $T_{B}, \lambda_{\text {TP }}$ and "equilibrating thyroidal plasma flow" ( $\left.\lambda_{\mathrm{PT}} \mathrm{V}\right)$ are given in Table I. In each case $\lambda_{\text {TP }}$ was evaluated from several points on the curves, as in Figure 3 , and an average taken of the several determinations.

Following equilibration with plasma iodide ${ }^{\mathbf{1 3 1}}$, trapped thyroidal iodide ${ }^{131}$ was discharged by the intravenous administration of 1.0 gram $\mathrm{NaSCN}$ given over a $1 \frac{1}{2}$ to 2 minute period. ${ }^{7}$ The disappearance of radioactivity from the thyroid under these conditions was almost always exponential with half times varying from 0.25 to 23 minutes (Figures 2, 3a, 5, Table I). The rate of discharge was always greater than that given by $\lambda_{\mathbf{T P}}$ (Table I). In several cases an attempt was made to slow down the rate of discharge by the administration of smaller doses of $\mathrm{NaSCN}$. However, the effect appeared to be simply a reduction in the fraction discharged; the rate of discharge of the radioactivity which disappeared remained unchanged (Figure 5).

\section{Thyroidal Iodide Binding}

The rate of binding of trapped iodide was evaluated from the results of three different types of

\footnotetext{
7 Although this dose of thiocyanate appeared to discharge all trapped iodide ${ }^{181}$, it is possible that a low thyroid/plasma ratio of 2 or 3 to 1 persisted. Since this would generally mean a thyroidal iodide space of only about 0.1 liter, the persisting thyroidal radioactivity after NaSCN would represent only a fraction of a per cent of the administered dose and would not be detectable by the methods used in this study.
}

experiments performed in the absence of Tapazole ${ }^{\circledR}$ block :

1) Determination of the thyroidal clearance rates of plasma iodide at different intervals during the half-hour period following administration of iodide ${ }^{\mathbf{1 8 1}}$;

2) Determination of the dischargeability of radioactive iodine from the thyroid by the intravenous injection of $\mathrm{NaSCN}$;

3) Determination of thyroidal iodide and the rate of binding according to the analysis presented above.

\section{Constancy of thyroidal clearance of plasma iodide}

When tracer iodide is administered in the absence of Tapazole block, thyroidal plasma iodide clearance rates remain relatively constant (Figures 3,6$)$. These observations confirm previous studies (7). It must be emphasized that in extremely active glands these measurements may be valid only for the first 15 to 20 minutes since by this time the thyroid may already be secreting some organically bound $\mathrm{I}^{181}$ as evidenced by the appearance of significant concentrations of $\mathrm{PBI}^{181}$ (compared to iodide ${ }^{131}$ ) in the plasma.

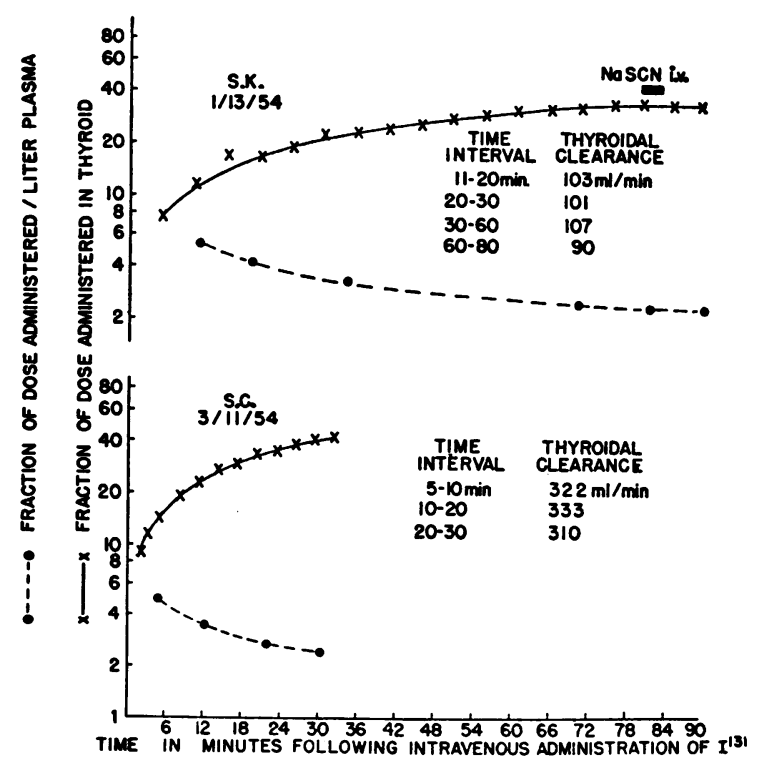

Fig. 6. Thyroidal and Plasma Radioactivities in

S. K. ANd S. C. During "Binding" Studies

Both subjects hyperthyroid. Thyroidal clearances remain constant throughout period of observations. See also H. W., Figure 3a. 
If there were an appreciable lag in binding of trapped iodide, iodine accumulation by the thyroid, binding permitted, would be a two-rate function. The clearance values should then decrease significantly with time. Since no detectable decrease was observed in these cases, the binding of trapped iodide was effected without significant time lag.

\section{Effect of NaSCN on thyroidal radioactivity in the absence of Tapazole inhibition}

That binding is, in fact, extremely rapid compared to trapping was repeatedly confirmed by the failure of $\mathrm{NaSCN}$ to discharge any thyroidal activity which had been accumulated more than one minute prior to the administration of the NaSCN (Figure 7). In all cases (17 subjects) where $\mathrm{NaSCN}$ was injected between 9 and 50 minutes after the $I^{131}$ tracer, no detectable decrease in thyroidal radioactivity was observed. D. $H$. is a possible exception. In two cases where thiocyanate was given at $4 \frac{1}{2}$ and 7 minutes (S. R. and J. J., respectively, Figure 7), there was evidence of discharge of some of the iodide accumulated during the period of thiocyanate injection, but not of any of the iodide accumulated prior to injection. The effectiveness of $\mathrm{NaSCN}$, in these doses, in rapidly discharging trapped iodide when it is present, is evident from the experiments in the same subjects and in others blocked with Tapazole (Figure 2).

The longevity of action of thiocyanate should be noted. In a number of cases a binding study was performed about a week after a trapping study in which thiocyanate had been used to discharge the iodide. In many of these cases the thyroidal radioactivities at early times during the binding study were actually lower than at corresponding times during the trapping study, apparently due to the inhibitory effect on iodide trapping by the

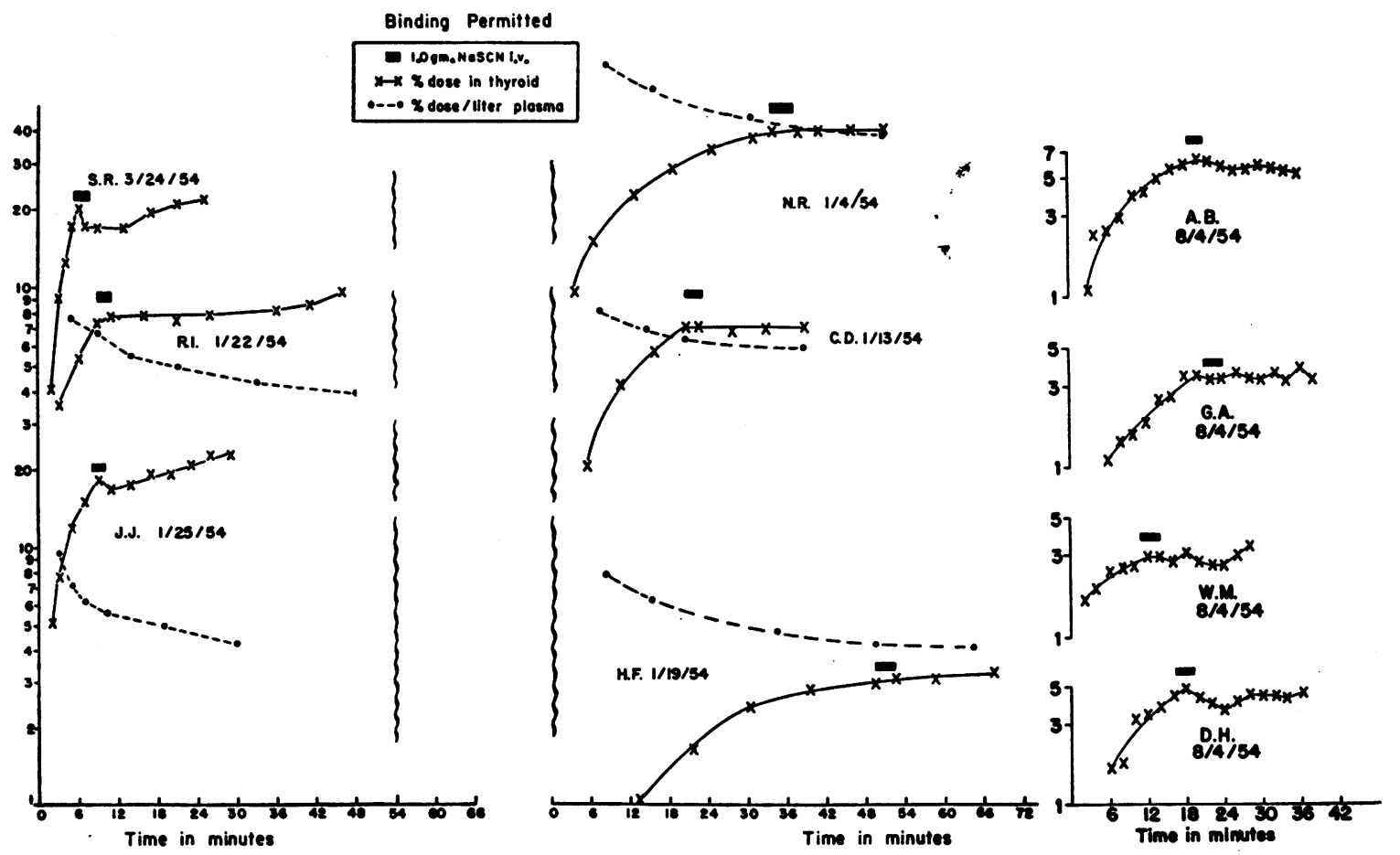

Fig. 7. The Effect of Thiocyanate on Im Accumulated by the Thyord in the Absence of Inhibition of Binding

First five subjects (S. R. to C. D.) hyperthyroid; last five subjects (H. F. to D. H.) euthyroid. In N. R. the plasma points should be read as $0.1 \times$ scale reading. The effect of $\mathrm{NaSCN}$ in discharging iodide ${ }^{2 \mathrm{x}}$ when present may be observed in Figure 2.

Because of the low uptakes in the euthyroid subjects there was a larger statistical error in the counting rates which accounts for the waviness of the plateau regions after thiocyanate in these cases. 
residual thiocyanate (compare, with dates, C. D., R. I., and J. J., Figure 7 and Figure 2). In a few cases thiocyanate given during the binding study appeared to inhibit completely further $I^{181}$ uptake for only a short time; after that the thyroidal uptake slowly increased (S. R., R. I., and J. J., Figure 7). Apparently the fall from peak thiocyanate concentration due to distribution into slower equilibrating extrathyroidal spaces was sufficient to allow escape of the thyroid trap from complete thiocyanate inhibition in these cases.

\section{Determination of the rate of binding according to the kinetic analysis}

To attempt a more precise evaluation of the rate of binding of trapped iodide, trapping and binding studies were performed on the same day in several patients, as described under Methods, and analyzed as in Figure 3. Since less than two hours elapsed between the two studies in these cases, the possibility of significant changes in blood flow, transfer rate constants, mean iodide diffusion paths, etc. can be disregarded and the results may be directly compared. Several sets of the curves obtained are shown in Figure 8. As expected, the initial slopes are virtually identical since at 0 time there is only a one way passage of $\mathrm{I}^{\mathbf{1 8 1}}$ (into the gland) whether or not binding occurs. Since the rate at which iodide ${ }^{\mathbf{1 8 1}}$ leaves the gland during the trapping studies $\left(\lambda_{\text {TP }}\right)$ is generally only 2 to 4 per cent per minute (Table I), it is not surprising also that the initial segments of the curves should appear to be virtually superimposable. In six previously untreated hyperthyroid patients, the analysis demonstrated that, when binding was uninhibited, no detectable amounts of iodide ${ }^{\mathbf{1 8 1}}$ were present in the gland at any time, at least after the first blood samples were withdrawn (as early as $31 / 2$ to 5 minutes). In none of these cases was it possible to construct any curve at all for thyroidal iodide ( $T$ ), small positive or negative values (within the limits of the experimental errors) being obtained at all points. These observations indicated that binding must have occurred almost instantaneously and that the thyroid/plasma gradient for exchangeable iodide must have been very low. Further confirmation that binding was virtually instantaneous is afforded by the almost identical values for the plasma iodide clearance rates and

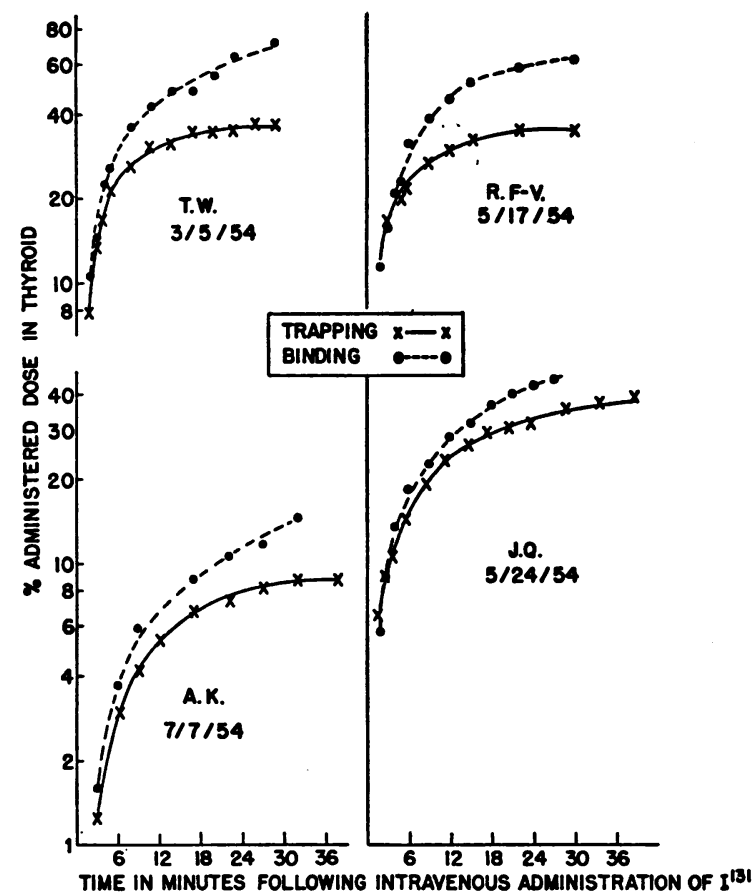

Fig. 8. Thyroidal Radionctivities (Per Cent Administered Dose) During Trapping and Binding Studies Performed on the Same Day in Each of Four HYPERTHYROID SUBJECTS

Fifty mg. Tapazole was given to each subject a few minutes after the last point on the binding curves. The trapping studies were performed 60 to 90 minutes later.

the equilibrating plasma flows (Table II, Figure 3).

Although it is obviously impossible to evaluate precisely the extremely rapid rate of binding of trapped iodide in these cases, the combined experience of the various types of observations suggests that this must be at least of the order of 50 to 100 per cent per minute.

\section{Partial inhibition of binding in a case of hyper- thyroidism treated with $I^{181}$}

Kirkland (10) has recently presented evidence for partial inhibition of binding in patients previously treated for hyperthyroidism with radioactive iodine, by demonstrating the partial dischargeability of thyroidal $\mathrm{I}^{\mathbf{1 8 1}}$ with sodium thiocyanate several hours after the administration of radioiodine. This observation is confirmed by the tracer studies in subject R. S. (Figure 4), in whom a therapeutic dose of $\mathrm{I}^{181}$ five months previously 

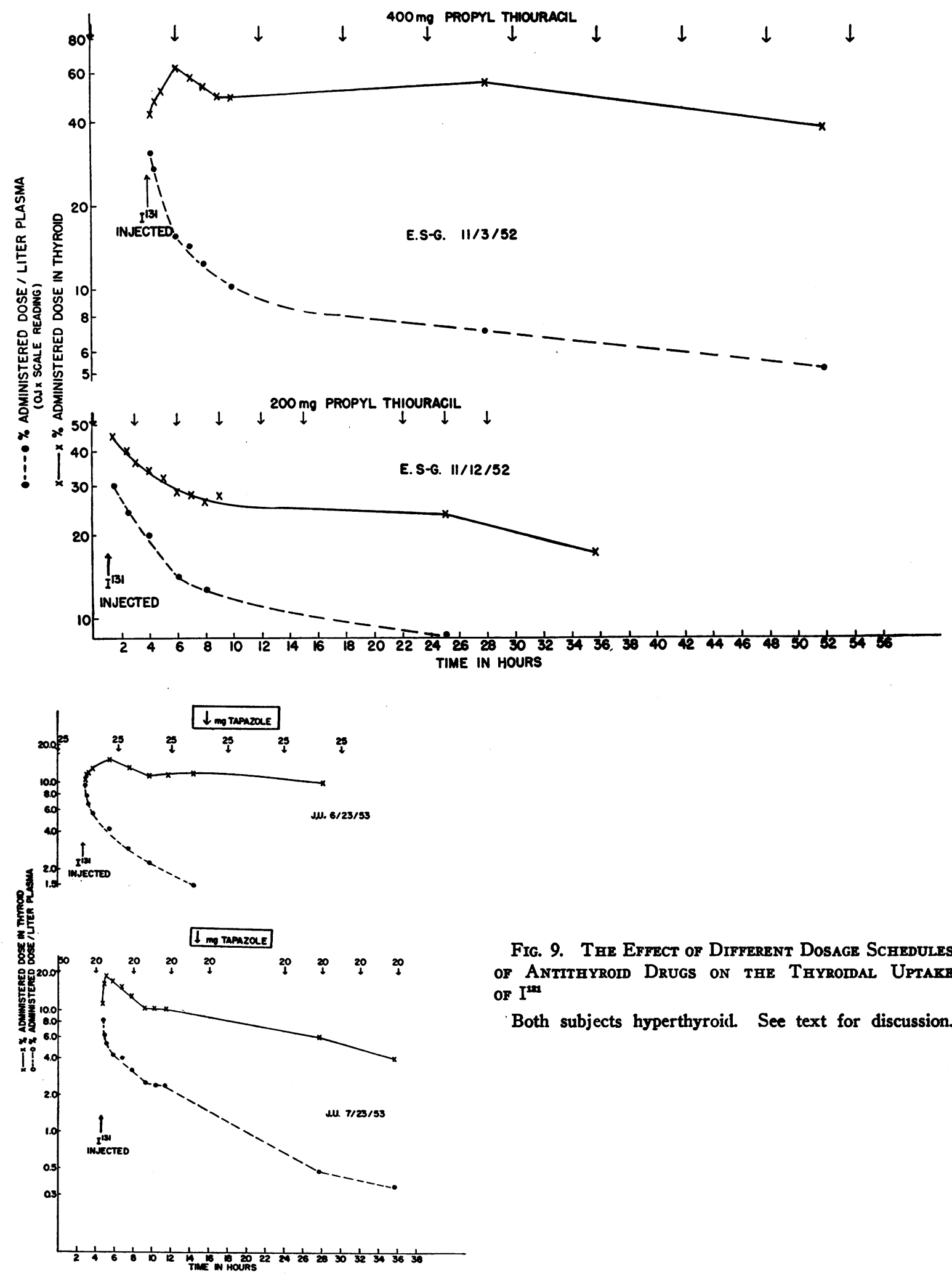

Fig. 9. The Efrect of Different Dosage Schedules of Anttihyroid Drugs on the Thyromal Uptake of In

Both subjects hyperthyroicl. See text for discussion. 
had failed to produce complete remission of thyrotoxicity. In this case, the equilibrating plasma flow (143 ml. per min.) was distinctly higher than the observed thyroid clearance rate after $10 \mathrm{~min}$ utes (86 ml. per min.). Analysis of the trapping and binding curves (Figure 4 ) revealed that there was a detectable amount of trapped iodide present throughout the period of the binding study and that binding of the trapped iodide proceeded at a rate of about 10 per cent per min. The thyroidal iodide space $\left(\mathrm{T}_{\mathrm{s}}\right)$ was 1.0 liters plasma equivalent as compared to 2.9 liters when binding was completely inhibited by Tapazole ${ }^{\circledR}$.

\section{Effect of Incomplete or Intermittent Inhibition of Binding by Antithyroid Drugs on the Thyroidal Uptake of Radioiodine}

At completely inhibitory dose levels of antithyroid drugs, only a small fraction of the administered radioactive iodine remains in the thyroid (as unbound iodide) after 24 hours or so. For Tapazole ${ }^{\circledR}$, a dosage schedule of 25 to $30 \mathrm{mg}$. every six hours has been found effective in reducing binding of radioactive iodine to less than 2 to 3 per cent of the administered dose in almost all cases. With smaller doses or longer intervals between doses a variable degree of binding is permitted and significant fractions of $\mathrm{I}^{\mathbf{1 3 1}}$ are found in the thyroid 24 to 48 hours after administration of the tracer. In Table III are given the 24-hour thyroidal $\mathrm{I}^{131}$ uptake values for a group of hyperthyroid subjects maintained for one to two weeks on different dosage schedules. In all cases the total daily dose was divided into four equal parts given at 6-hour intervals. The 24-hour values observed are actually slightly in excess of the amounts bound in organic form, since a small fraction of thyroidal radioactivity at 24 hours (usually less than 3 to 4 per cent of the administered dose) is still unbound iodide. Furthermore, the results are not always directly comparable since in any individual test the fraction bound depends on the time of administration of the tracer with respect to the previous dose of antithyroid agent. However, the results demonstrate that in general the fraction of administered iodide ${ }^{\mathbf{1 3 1}}$ which is bound decreases as the dose level is increased. Ten mg. of Tapazole ${ }^{\circledR}$ per day appeared to be almost totally ineffective and even $40 \mathrm{mg}$.
TABLE II

Comparison of equilibrating plasma flow and thyroidal clearance rates

\begin{tabular}{lccc}
\hline \hline Subject & Date & $\begin{array}{c}\text { Trapping study } \\
\text { Equilibrating } \\
\text { plasma flow }\end{array}$ & $\begin{array}{c}\text { Binding study } \\
\text { Thyroidal } \\
\text { clearance }\end{array}$ \\
\hline & $5 / 24 / 54$ & ml./min. & ml./min. \\
J. Q. & $5 / 26 / 54$ & 390 & 347 \\
H. W. & $3 / 5 / 54$ & 634 & 650 \\
T. W. & $7 / 7 / 54$ & 553 & 540 \\
A. K. & $3 / 16 / 54$ & 87 & 85 \\
V. C. & $4 / 26 / 54$ & 700 & 167 \\
R. F-V.* & $5 / 17 / 54$ & 430 & 800 \\
& $3 / 10 / 54$ & 143 & 456 \\
R. S. $\dagger$ & & & 86
\end{tabular}

* Treated with Tapazole ${ }^{\circledR}$ 4/26/54-5/13/54.

† Treated with 8 mc. I ${ }^{131} 10 / 15 / 53$.

per day not infrequently allowed for binding of about $1 / 3$ the administered dose. Similar results have been well documented by Stanley and Astwood (3).

That high uptake of $\mathrm{I}^{131}$ under treatment with the antithyroid drugs is not to be explained by intrinsic thyroidal refractoriness to these agents is clear from the effect of increasing dose levels in the same subjects (Table II), and is further demonstrated by the two cases shown in Figure 9. In subject S. G. $400 \mathrm{mg}$. propylthiouracil every 6 hours permitted uptake of over 50 per cent of the tracer at 24 hours. When the same total daily dosage was divided into amounts of $200 \mathrm{mg}$. every 3 hours, inhibition of binding was much more effective, only 20 per cent remaining at 24 hours. It is to be noted that in the first test, the radioiodine was administered 5 hours after the last dose of propylthiouracil so that a large fraction of the $\mathrm{I}^{131}$ was bound before the next dose of propylthiouracil took effect. Apparently the effective duration of action of propylthiouracil in this case was between 3 and 5 hours. In other cases of hyperthyroidism, $200 \mathrm{mg}$. propylthiouracil every 3 hours has been effective in inhibiting almost completely the binding of iodide ${ }^{131}$. In case J. U., complete inhibition of binding was not effected by $25 \mathrm{mg}$. of Tapazole every 6 hours and 10 per cent of the dose was retained in the thyroid at 24 hours. By administering an extra $50 \mathrm{mg}$. before the test and $20 \mathrm{mg}$. every 4 hours during the day, the amount retained at 24 hours was reduced to 4 per cent (Figure 7). As suggested by the thyroid and blood curves, about 3 per cent of the ad- 
TABLE III

Effect of varying daily dosages of Tapazole (1) on the 24-hour uptake of $I^{\text {in }}$ (per cent of dose) *

\begin{tabular}{|c|c|c|c|c|c|c|c|}
\hline Subject & mg./day.... o & 10 & 15 & 20 & 30 & 40 & 60 \\
\hline $\begin{array}{l}\text { R.T. } \\
\text { L.Fa. } \\
\text { P.S. } \\
\text { W.W. } \\
\text { E. McI. } \\
\text { C. T. } \\
\text { P.R. } \\
\text { H. B. } \\
\text { V.S. } \\
\text { T. B. } \\
\text { A.C. } \\
\text { J. Lo. } \\
\text { L. Fe. } \\
\text { J. J. } \\
\text { E. K. } \\
\text { L. D. M. } \\
\text { M.G. } \\
\text { J. Lu. } \\
\text { A.I. } \\
\text { J. B. } \\
\text { A.F. } \\
\text { J. D. }\end{array}$ & $\begin{array}{l}63 \\
75,84 \\
83 \\
84 \\
95,77,82 \\
84 \\
79 \\
74 \\
83,79,78 \\
80 \\
90,83 \\
83 \\
71,72 \\
77 \\
75 \\
47,44 \\
78 \\
90 \\
77 \\
61 \\
84,91 \\
82\end{array}$ & 59,65 & 15,26 & $\begin{array}{l}27 \\
46 \\
25 \\
37,35 \\
24 \\
53 \\
72 \\
26\end{array}$ & $\begin{array}{l}46 \\
25 \\
37 \\
50 \\
28 \\
34,26 \\
27 \\
36,28 \\
24,22 \\
16 \\
20,21 \\
31,34 \\
19 \\
13 \\
28,26,28,29\end{array}$ & $\begin{array}{l}30 \\
35 \\
23\end{array}$ & 17 \\
\hline
\end{tabular}

* Total daily dose divided into four equal quantities at 6-hour intervals. I $^{1 \mathrm{n}}$ tracer tests performed without discontinuing therapy after 1 to 2 weeks on the dosage schedule indicated. The 0 column indicates the values obtained prior to therapy or during a therapy-free interval.

ministered $\mathrm{I}^{131}$ was apparently bound during the night of the second test when a dose of Tapazole was omitted. This was the only case observed in the present series in which $25 \mathrm{mg}$. Tapazole every 6 hours permitted a detectable quantity of $I^{181}$ to be bound.

\section{DISCUSSION}

\section{Rate of Thyroidal Trapping of Iodide}

The significant parameter for iodide trapping appears to be what has been here termed the equilibrating thyroidal plasma flow, in effect, an hypothetical volume flow from which the thyroid trap extracts all the iodide. When organic binding is completely blocked, an equal amount of iodide is returned to the plasma (at equilibrium) but in the absence of inhibition of binding this amount of iodide is quantitatively converted to organic form. It cannot be denied that some minute fraction of trapped iodide may be returned to the plasma without being bound in the thyroid but the findings presented in this study indicate that it is generally undetectable. There are special circumstances, however, where binding is not so efficient. Kirkland's report on inhibition of binding in glands previously subjected to significant radiation from $I^{181}$ has already been cited and a case illustrating this situation has been presented. Iodide and the antithyroid drugs also, of course, inhibit binding. In addition to these examples of induced inhibition of binding there are instances of spontaneous physiologic or pathologic block to binding, such as the inability of the 7-day chick embryo thyroid to bind the iodide it is capable of trapping (11) and the limited binding of iodide trapped by the thyroids of certain goitrous cretins $(12,13)$. These cases must be distinguished, however, from the usual euthyroid or hyperthyroid subject whose gland appears to be capable of binding virtually all the iodide which is trapped before it can escape back to the plasma. In these cases, then, it is the rate of trapping rather than the rate of binding which is the limiting step in thyroidal iodine accumulation.

In discussing the trapping rate process it may be questioned whether it is not more pertinent to evaluate the quantity of $\mathrm{I}^{127}$ trapped per unit time than to consider only $\mathrm{I}^{181}$ transfer. However, experiments have been performed with carrier doses of iodide ${ }^{127}$ several hundred times the exchangeable iodide ${ }^{127}$ present in the body without affecting the equilibrating plasma flow rates or the $T_{\text {s }}$ val- 
ues (14)..$^{8}$ Under these conditions the hyperplastic thyroid is capable of trapping several hundred micrograms iodide ${ }^{127}$ per minute. Thus, the thyroid trap is usually operating far below its capacity for iodide ${ }^{127}$ at transfer rates which are independent of the serum iodide ${ }^{127}$ concentrations within wide limits of the latter.

\section{Thyroidal clearance of plasma iodide and the roles of trapping and binding}

Myant, Pochin, and Goldie (15) and Berson, Yalow, Sorrentino, and Roswit (7) noted that the thyroidal clearance of plasma iodide ${ }^{131}$ remained fairly constant over periods of several hours after the administration of $I^{131}$. This constancy was observed even when clearance rates during the first and second 15-minute periods were compared with those from $1 / 2$ to 3 hours following intravenous injection of radioiodine (7). It was, therefore, tacitly assumed that thyroidal clearance of iodide was a single rate function. The same assumption is implicit in the studies of Stanley (16) and of Keating and Albert (17). It has furthermore been assumed in these studies that the product of the rate of thyroidal plasma iodide ${ }^{131}$ clearance and the plasma iodide ${ }^{127}$ concentration may be considered quantitatively equal to the rate of hormonal iodine synthesis in the absence of spontaneous or induced block of synthesis.

More recently, Ingbar (4) has stated that the rate of thyroidal clearance of plasma iodide as calculated by previous investigators does not indicate the rate of transfer of plasma iodide to hormonal iodine. He has calculated that the average rate of binding of trapped thyroidal iodide is only $11 / 2$ per cent per minute in euthyroid and $61 / 2$ per cent per minute in hyperthyroid subjects. However, if this were true a very large fraction of thyroidal radioactivity should be in the form of exchangeable unbound iodide for some time after injection of $\mathrm{I}^{181}$. The inability of $\mathrm{NaSCN}$ to discharge any significant fraction of radioactivity as observed in the cases presented here and in the studies of VanderLaan (18) offers strong evidence against the correctness of Ingbar's calculations. Moreover, Ingbar's studies were based

\footnotetext{
8 These observations refer only to acute experiments. Physiologic adjustments to continued treatment with iodide are not under consideration here.
}

on a number of questionable assumptions. His analysis assumes that, in unblocked glands, the total counting rate over the neck two minutes after the intravenous injection of iodide ${ }^{131}$ can be taken to represent unbound thyroidal iodide ${ }^{\mathbf{1 3 1}}$ without correction for extrathyroidal radioactivity. Employing this value, the thyroidal iodide space at that time is then calculated, not from the actual plasma concentration, but from the 0 time exponential extrapolation of the late plasma curve. It is further assumed that the thyroid/plasma ratio remains constant thereafter and that thyroidal iodide $^{\mathbf{1 3 1}}$ at any time therefore can be calculated from the exponential extrapolation of the late plasma curve. These assumptions are unjustified and can be shown to be invalid.

The theoretical analysis presented by Wollman (6) requires that the plasma iodide ${ }^{131}$ concentration remain constant or decrease at a single exponential rate. Since the plasma concentration does not (and, theoretically, cannot) decrease exponentially during equilibration with the thyroid trap, the formulas derived cannot be directly applied to the precise analysis of data obtained following a single injection of $\mathrm{I}^{131}$. The possibility of approaching the problem through the maintenance of constant plasma concentrations by continuous infusion techniques remains to be explored but would appear to be difficult since removal from the plasma is not constant. However, the method of analysis developed in the present report appears to satisfactorily resolve the difficulty of changing plasma concentrations.

Wollman's theoretical analysis can be recommended for its evaluation of the consequences of non-instantaneous equilibration of the thyroid trap. However, he concludes that "if equilibration cannot be considered instantaneous ... the thyroid clearance of radioiodide from the blood will not be a constant independent of the time after injection." The observations presented here demonstrate that, in untreated glands, thyroid clearance is a constant for all practical purposes, because of the extremely rapid rate of binding.

\section{Possible factors in the limitation of iodide trapping}

To our knowledge, there have not been reported any data relative to the iodine extraction ratio in human hyperplastic thyroid glands. However, 
since thyroidal plasma iodide ${ }^{131}$ clearance rates of $1200 \mathrm{ml}$. per min. have been observed in this laboratory, and even higher values have been reported by Myant, Pochin, and Goldie (15), it appears highly improbable that extraction is much less than completely efficient in these cases, unless the blood flow to the thyroid is to equal or exceed that to the rest of the body. In such cases then, it is suggested that iodide trapping is, at least in great part, limited by the blood flow. In the less active gland, however, the importance of other factors in limiting the rate of iodide trapping may be inferred from the following considerations.

The mean normal thyroidal plasma iodide ${ }^{131}$ clearance rate is approximately $17 \mathrm{ml}$. per min. $(7,15)$. From values for iodide ${ }^{127}$ excretion, renal clearance and daily hormonal requirements, Riggs arrives at a fairly similar estimate of 18.8 $\mathrm{ml}$. per min. for the thyroidal clearance of iodide (19). Means (20) has estimated the normal thyroid mass at $20 \mathrm{gm}$. and blood flow at $4 \mathrm{ml}$. per gm. per min., implying a total thyroidal blood flow of $80 \mathrm{ml}$. per min. Using these estimates and assuming that $\mathrm{RBC}$ iodide is directly available to the thyroid, the values for thyroidal plasma clearance (employing an hematocrit of 45 per cent) indicate an extraction ratio of only 27 per cent in the normal gland. These figures are in good agreement with Pochin's direct observations on the normal lobe during surgical removal of nontoxic adenomata which gave a mean extraction ratio of 20 per cent (21).

Thus, it would appear that other factors, in addition to blood flow, probably contribute to the limitation of iodide trapping in the normal gland. The factors to be considered are those concerned with passage of iodide from the blood stream to the thyroid trap as well as possible limitations of the trapping mechanism for stable iodide. The possibility that overloading of the trapping mechanism is responsible for limiting the rate of iodide trapping in these cases has been rendered very unlikely by the experiments previously cited with large doses of iodide ${ }^{127}$ in which it was observed that in the same gland, amounts of iodide ${ }^{127}$ extending throughout ranges of 100 -fold and greater are trapped at identical equilibrating plasma flow rates and thyroid/plasma ratios (14).

Analysis of the passage of iodide from the capillary to the trap cannot be reduced to simple terms.
Schmidt $(22,23)$ has mathematically formulated the relevant factors involved in the rate of equilibration of molecules diffusing from blood to tissue, and Cotlove (24) recently has presented an elegant analysis of a number of special cases of extracellularly distributed substances. The factors involved, in addition to those concerned with blood flow, include the total capillary wall area, the permeability coefficient of the capillary wall to the particular molecule, the diffusion path length (here, the distance from the capillary to the trapping site). and the extent of reduction of the free diffusion coefficient due to geometrical and other peculiarities of the tissue (e.g., the increase in diffusion path length over the straight line distance, necessitated by passage around fibers, etc.). Unfortunately there are no data for the thyroid available for any of these factors. Pitt-Rivers and Trotter (25) have presented evidence that in the thiouracil blocked gland the entire colloid area is the site of trapped iodide. Measurements of the straight line path between the capillary and the trapping site could be made without difficulty, and significant differences in follicular diameter of normal and hyperplastic glands might then be seen to be influential. However, there is no information available concerning the degree of hindrance of the colloid to the diffusion of iodide. Whether the diffusion coefficient of iodide in the colloid is reduced significantly below the free diffusion coefficient may be critical to the calculations and should be answered by future in vitro studies. The report by De Robertis (26) that the viscosity of the colloid diminishes after the injection of thyrotropic extracts of the pituitary may be pertinent in this regard. Whether the permeability coefficient of the thyroidal capillaries for iodide is a constant at varying levels of thyroidal activity is also unknown. Furthermore, in addition to the parameters concerned with equilibration in the extracellular tissues of the thyroid, there is the factor of iodide passage through or between the follicle cells to the colloid. The permeability of the follicle cells to iodide may be an important regulatory factor in the trapping of iodide. The present state of knowledge of these relevant physiologic problems does not permit even a guess as to the critical factors involved in the limitation of iodide trapping. Perhaps the 
questions raised may point the way to future avenues of investigation.

\section{Non-Exchangeable Thyroidal Iodide}

Riggs (19) has estimated the average plasma iodide level of persons living in New England at approximately 3 micrograms per liter. Estimations of the plasma iodide concentrations in several patients of the present study (E. G., S. K., N. R.) have been given elsewhere (27), and were observed to be of the same order of magnitude. In these hyperthyroid subjects under the effects of Tapazole ${ }^{\circledR}$ block, exchangeable thyroidal iodide never exceeded 36 liters plasma equivalent or 108 micrograms iodide; in most cases, values of $10 \mathrm{mi}$ crograms or less would appear to represent the amount of exchangeable iodide present in the thyroid when binding is blocked. In unblocked normal or hyperfunctioning glands, moreover, the quantity of exchangeable thyroidal iodide must be significantly less. Yet much greater amounts of iodide have been found in the untreated thyroid on direct chemical analysis. Gutman, Benedict, Baxter, and Palmer (28) reported an average value of 580 micrograms for inorganic iodide on human thyroid glands obtained from apparently normal individuals who had met with sudden death. Braasch, Albert, Keating, and Black (29) have observed that approximately 6 to 7 per cent of total thyroidal $\mathrm{I}^{127}$ and $\mathrm{I}^{131}$ is identifiable as iodide on column chromatography of trypsin-hydrolyzed material or that approximately 1,000 micrograms of iodide are present as a maximum in the untreated thyroid gland of euthyroid and hyperthyroid subjects. Utilizing the techniques of filter paper partition chromatography on saline and trichloracetic acid extracts of rat, rabbit, sheep, and dog thyroids, Taurog, Tong, and Chaikoff (30) found that inorganic iodide constituted only about 1 per cent of total thyroidal iodine in these animals. However, even this latter value represents a very much larger quantity of thyroidal iodide than is derived by estimations from the equilibration studies with radioactive iodine. Therefore, if the finding of these large amounts of inorganic iodide on chemical analysis cannot be attributed to breakdown of organic iodine in the separation procedures utilized or to other artifacts, it must be concluded that the major portion of thyroidal iodide is not readily exchangeable with the iodide of the plasma. It is interesting to speculate whether this unexchangeable iodide exists in the colloid side by side with exchangeable iodide or resides only in adjacent inactive follicles.

\section{The Kinetics of Iodide Discharge by Thiocyanate}

It is likely that the mechanism of action of thiocyanate in discharging trapped thyroidal iodide will not be defined precisely until more is known about the fundamental nature of the iodide trap itself. However, several interesting observations of the kinetics of iodide discharge by thiocyanate merit consideration.

$A$ priori, the possibility of three general hypothetical mechanisms for the action of thiocyanate may be postulated :

1. Thiocyanate prevents further entry of iodide into the trap but does not actively discharge the trap.

2. Thiocyanate actively discharges the trap.

3. Thiocyanate neither prevents iodide trapping nor discharges the trap but merely competes with iodide within the trap.

Either or both of the first two actions could be effected through an iodide trapping enzyme system if such exists.

The rapid rate of discharge of iodide by thiocyanate serves to exclude the first hypothesis. For, if thiocyanate merely prevented further iodide trapping, the rate of discharge by thiocyanate should have been identical to the transfer rate of iodide from thyroid to blood $\left(\lambda_{\text {TP }}\right)$ determined during the equilibration period. In all cases the rate of discharge by $\mathrm{SCN}^{-}$was greater than $\lambda_{\mathrm{TP}}$ and, in some instances, ten or more times as great.

The third mechanism has been suggested by Baumann and Metzger (31) on the basis of the similarity of behaviour of iodine and thiocyanate in the Hoffmeister series and other chemical likenesses. It has been stated that iodide concentration by the thyroid is not unique and that other halides and thiocyanate are also concentrated (31). Although it has been reported by others (32) that there is no thyroid/plasma concentration gradient for thiocyanate ion, this in itself does not exclude the competition theory. The administration of approximately 500,000 to $1,000,000$ micrograms of 
thiocyanate is generally required to discharge all the trapped iodide. On the basis of a space of distribution of 25 per cent of body weight in a $70 \mathrm{~kg}$. man, one gram of $\mathrm{NaSCN}$ would give a concentration of 70 micromoles per cent in the plasma. If the same concentration were achieved in a 100 gram thyroid, $\mathrm{SCN}^{-}$ion could simply, by substitution mole for mole, wash out almost 99 per cent of the less than 1.0 micromole of exchangeable iodide usually present in the blocked gland. Moreover, it is conceivable that one mole of thiocyanate could substitute for a number of moles of iodide. The exponential nature of the discharge curve, which is suggestive of an exchange or turnover reaction, and the unchanging rate of discharge when different amounts of thiocyanate were used to release different fractions of thyroidal iodide, are consistent with the competition hypothesis. However, certain experimental observations fail to add support. The same dose of thiocyanate is capable of discharging, entirely, milligram amounts of iodide from thyroids equilibrated with large carrier doses of $\mathrm{I}^{127}$ (14), which is not consonant with the concept that the graded amounts of thiocyanate were required to discharge by replacement only a few additional micrograms. This observation suggests that thiocyanate acts in a quantitative manner on some part of the iodide trapping mechanism which is independent of the amount of iodide trapped. For example, an individual locus of trapping may be able to hold a variable number of iodide ions. The presence of a single thiocyanate radicle however might exclude any iodide ions from that locus. This should not be interpreted as a substitution phenomenon but rather as an active discharge of the trapped iodide or a poisoning (albeit temporary) of the iodide trapping site.

The experimental observations and foregoing speculations therefore suggest that sodium thiocyanate actively discharges iodide from the thyroid. If so, it seems difficult to interpret the exponential character of the iodide discharge curve in any other way than by postulating a sudden release of iodide from the thyroid trap followed by a "wash out" of the iodide. In some hyperthyroid cases, at least, the rate of "wash out" was too slow to be limited by blood flow since in many of these cases flows of $500 \mathrm{ml}$. per min. or more were perfusing glands of only 50 to 100 grams. If diffusion equilibrium within the gland were instantaneous, the half times for discharge should then have been only of the order of seconds, rather than minutes as observed. The discharge of iodide by thiocyanate, therefore, is, in all probability, chiefly diffusion and/or permeability limited which suggests that these factors play some role in the accumulation process as well.

\section{SUM MARY AND CONCLUSIONS}

1. A method is presented for the kinetic analysis of thyroidal iodide trapping and binding in vivo.

2. Radioiodide transfer between thyroid and plasma in both directions was determined in a group of subjects under conditions in which organic iodine binding was effectively blocked.

3. In the absence of block of iodide binding, thyroidal plasma clearance of iodide ${ }^{131}$ is essentially constant and the thyroid/plasma iodide ${ }^{181}$ ratio is too small to be measured (by the in vivo techniques employed here) in hyperthyroid as well as euthyroid subjects.

4. Thyroidal plasma iodide clearance in the unblocked gland is equal to that volume flow of plasma whose iodide content is transferred to the thyroid trap in the blocked gland. This indicates that iodide trapped by the thyroid is bound before significant loss back to the plasma can occur. Further confirmation of the efficiency and rapidity of binding of trapped iodide by the untreated gland is presented in experiments demonstrating the absence of discharge, by thiocyanate, of any significant fraction of accumulated thyroidal radioactivity even a few minutes after the injection of radioactive iodine.

5. Factors possibly limiting thyroidal iodide trapping have been discussed in terms of blood flow, permeability and diffusion and are considered inadequately defined in the quantitative aspects at present to justify conclusions regarding their relative significance.

6. Possible mechanisms of thiocyanate discharge of trapped thyroidal iodide have been considered. The quantitative experimental data presented favor the interpretation of an inactivation of the thyroid trap by thiocyanate in preference to that of a simple substitution of thiocyanate for iodide. 
7. The effect of different dosage regimens of 1-methyl-2 mercaptoimidazole on iodide binding and on the character of the thyroidal $\mathrm{I}^{131}$ uptake curves is presented.

\section{APPENDIX}

\section{Alternative Analysis of Iodide Trapping}

Let $\mathrm{T}$ and $\mathrm{P}$ be total thyroidal iodide ${ }^{121}$ and iodide ${ }^{131}$ concentration in the plasma, respectively, and $\mathrm{T}^{*}$ and $\mathrm{P}^{*}$ be total exchangeable thyroidal iodide ${ }^{17}$ and iodide ${ }^{177}$ concentration in plasma, respectively, at any time, t. Also, let $T_{*}^{*}=\frac{T^{*}}{P^{*}}$ and $V$ be the plasma volume. Then,

$$
\frac{d T}{d t}=-\lambda_{T P} T+\lambda_{P T} P V
$$

In the steady state,

$$
\lambda_{\mathrm{TP}} \mathrm{T}^{*}=\lambda_{\mathrm{PT}} \mathrm{P}^{*} \mathrm{~V}
$$

and

$$
\lambda_{\mathrm{TP}} \mathrm{T}_{0}^{*}=\lambda_{\mathrm{PT}} \mathrm{V}
$$

Substituting for $\lambda_{\mathrm{PT} V} \mathrm{in}$ (1),

$$
\frac{d T}{d t}=-\lambda_{T P} T+\lambda_{T P} T_{*}^{*} P
$$

Solving for $\lambda_{\text {TP }}$,

$$
\lambda_{T P}=\frac{d T / d t}{T_{0}^{*} P-T}
$$

At distribution equilibrium, $\frac{T}{P}$ is approximately equal to $\frac{\mathrm{T}^{*}}{\mathrm{P}^{*}}$ (see below), so that

$$
\lambda_{\mathrm{TP}} \cong \frac{\mathrm{dT} / \mathrm{dt}}{\mathrm{T} \mathrm{P}-\mathrm{T}}
$$

where $T_{0}$ is the equilibrium value for $\frac{T}{P}$.

Since there is continual loss of $I^{131}$ from the body by renal excretion, the equilibrium thyroid/plasma ratio for $I^{181}$ exceeds slightly that for $I^{127}$ as follows: From (1)

$$
\frac{\mathrm{dT} / \mathrm{dt}}{\mathrm{T}}=-\lambda_{\mathrm{TP}}+\lambda_{\mathrm{PTV}} \frac{\mathrm{P}}{\mathrm{T}}
$$

After distribution equilibrium is attained the fractional rate of decrease of thyroidal $\mathrm{I}^{131},\left(\frac{\mathrm{dT} / \mathrm{dt}}{\mathrm{T}}\right)$, is constant and equal to the fractional rate of loss of total body ${ }^{131}$. Let the rate constant of loss from the body after equilibrium be $K$, and substituting in ( $(\sigma), K=-\lambda_{\mathrm{TP}}+\lambda_{\mathrm{PTV}} \frac{\mathrm{P}}{\mathrm{T}}$. Then, $T_{0}\left(K+\lambda_{T P}\right)=\lambda_{P T V}$, and from (2),

$$
\frac{T_{0}}{T_{*}^{*}}=\frac{\lambda_{T P}}{\lambda_{T P}+K}
$$

The rate constant of excretion after distribution equilibrium (K), in the hyperthyroid subjects studied, ranged from $0.0005 \mathrm{~min}^{-1}$ to $0.0010 \mathrm{~min}^{-1}$ (3 to 6 per cent per hr.) while the values for $\lambda_{T P}$ fell between $0.0155 \mathrm{~min}^{-1}$ and 0.099 min. $^{-1}$ (see Table I). Thus, it is seen from equation 7 that $T_{8}$ exceeds $T_{0}^{*}$ ( $K$ is a negative quantity) by an average of about 1 per cent and never more than by about 6 per cent. By substituting in (7) the values obtained for $\lambda_{T P}, K$ and $T_{0}$ in any particular case, $T_{*}^{*}$ may be determined almost precisely. By substituting this value for $T_{*}^{*}$ in equation (4), $\lambda_{\text {TP }}$ may now be recalculated, to yield a value into which an error of less than 1 per cent is introduced by the theoretical analysis.

\section{ACKNOWLEDGMENTS}

We wish to thank Mr. John Hessian and Mr. Paul Newman for the illustrations, and Miss Eve Spelke and Mrs. Frieda Steiner for secretarial assistance.

We are also indebted to Mr. Raphael Cohen of WarnerChilcott Laboratories for assistance received in this study.

\section{REFERENCES}

1. McGinty, D. A., and Sharp, E. A., Effect of iodine intake on thyroid iodine distribution and thyroid weight of rats treated with thiouracil and other goitrogens. J. Clin. Endocrinol., 1946, 6, 473.

2. VanderLaan, J. E., and VanderLaan, W. P., The iodide concentrating mechanism of the rat thyroid and its inhibition by thiocyanate. Endocrinology, 1947, 40, 403.

3. Stanley, M. M., and Astwood, E. B., The accumulation of radioactive iodide by the thyroid gland in normal and thyrotoxic subjects and the effect of thiocyanate on its discharge. Endocrinology, 1948, 42, 107.

4. Ingbar, S. H., A new method for the study of thyroidal function in man, using radioactive iodine. J. Clin. Invest., 1953, 32, 577.

5. Ingbar, S. H., Simultaneous measurement of the iodide-concentrating and protein-binding capacities of the human thyroid gland. Transactions of the American Goiter Association, May 7-9. Springfield, Charles C Thomas, 1953, p. 387-401.

6. Wollman, S. H., A thyroid model describing kinetics of exchange, concentrating, and organic binding of iodide. Endocrinology, 1954, 54, 35.

7. Berson, S. A., Yalow, R. S., Sorrentino, J., and Roswit, B., The determination of thyroidal and renal plasma $\mathrm{I}^{121}$ clearance rates as a routine diagnostic test of thyroid dysfunction. J. Clin. Invest., 1952, 31, 141.

8. Berson, S. A., Yalow, R. S., Post, J., Wisham, L. H., Newerly, K. N., Villazon, M. J., and Vazquez, O. N., Distribution and fate of intravenously administered modified human globin and its effect on blood volume. Studies utilizing $I^{121}$ tagged globin. J. Clin. Invest., 1953, 32, 22. 
9. White, W. E., The rate of formation of nondiffusible (organic) fraction of $I^{121}$ in plasma correlated with apparent thyroid state. J. Lab. \& Clin. Med., 1953, 41, 516.

10. Kirkland, R. H., Impaired organic binding of radioiodine by the thyroid following radioiodine treatment of hyperthyroidism. J. Clin. Endocrinol. \& Metab., 1954, 14, 565.

11. Wollman, S. H., and Zwilling, E., Radioiodine metabolism in the chick embryo. Endocrinology, 1953, $52,526$.

12. Stanbury, J. B., and Hedge, A. N., A study of a family of goitrous cretins. J. Clin. Endocrinol., 1950, 10, 1471.

13. Stanbury, J. B., Cretinism with goiter: A case report. J. Clin. Endocrinol., 1951, 11, 740.

14. Berson, S. A., Yalow, R. S., Bauman, A., and Rothschild, M., Unpublished observations.

15. Myant, N. B., Pochin, E. E., and Goldie, A. E. G., The plasma iodide clearance rate of the human thyroid. Clin. Sc., 1949, 8, 109.

16. Stanley, M. M., The direct estimation of the rate of thyroid hormone formation in man. The effect of the iodide ion on thyroid iodine utilization. J. Clin. Endocrinol., 1949, 9, 941.

17. Keating, F. R., Jr., and Albert, A., The metabolism of iodine in man as disclosed with the use of radioiodine. Recent progress in hormone research. The Proceeding of the Louventian Hormone Conference, ed. by G. Pincus. New York, Academic Press Inc., 1949, vol. 4, p. 429.

18. VanderLaan, W. P., The biological significance of the iodide-concentrating mechanism. Symposium on the thyroid. Brookhaven National Laboratory, June 9-11, 1954. In press.

19. Riggs, D. S., Quantitative aspects of iodine metabolism in man. Pharmacological Reviews, 1952, 4, 284.

20. Means, J. H., The Thyroid and Its Diseases. 2nd Ed., Philadelphia, J. B. Lippincott Co., 1948.

21. Pochin, E. E., Investigation of thyroid function and disease with radioactive iodine. Lancet, 1950, $2,41$.
22. Schmidt, G. W., A mathematical theory of capillary exchange as a function of tissue structure. Bull. Math. Biophysics, 1952, 14, 229.

23. Schmidt, G. W., The time course of capillary exchange. Bull. Math. Biophysics, 1953, 15, 477.

24. Cotlove, E., Mechanism and extent of distribution of inulin and sucrose in chloride space of tissues. Am. J. Physiol., 1954, 176, 396.

25. Pitt-Rivers, R., and Trotter, W. R., The site of accumulation of iodide in the thyroid of rats treated with thiouracil. Lancet, 1953, 2, 918.

26. De Robertis, E., Proteolytic enzyme activity of colloid extracted from single follicles of the rat thyroid. Anat. Rec., 1941, 80, 219.

27. Berson, S. A., and Yalow, R. S., Quantitative aspects of iodine metabolism. The exchangeable organic iodine pool, and the rates of thyroidal secretion, peripheral degradation and fecal excretion of endogenously synthesized organically bound iodine. J. Clin. Invest., 1954, 33, 1533.

28. Gutman, A. B., Benedict, E. M., Baxter, B., and Palmer, W. W., The effect of administration of iodine on the total iodine, inorganic iodine, and thyroxine content of the pathological thyroid gland. J. Biol. Chem., 1932, 97, 303.

29. Braasch, J. W., Albert, A., Keating, F. R., Jr., and Black, B. M., A note on the iodinated constituents of normal thyroids and of exophthalmic goiters. J. Clin. Endocrinol. \& Metab., To be published.

30. Taurog, A., Tong, W., and Chaikoff, I. L., Non-thyroglobulin iodine of the thyroid gland. II. Inorganic iodide. J. Biol. Chem., 1951, 191, 677.

31. Baumann, E. J., and Metzger, N., Behavior of the thyroid toward elements of the seventh periodic group. I. Halogens and thiocyanates. Proc. Soc. Exper. Biol. \& Med., 1949, 70, 536.

32. Wood, J. L., and Williams, E. F., Jr., The metabolism of thiocyanate in the rat and its inhibition by propylthiouracil. J. Biol. Chem., 1949, 177, 59. 